\title{
What is the future of assertive community treatment?
}

\author{
PETER TYRER
}

Although the trend towards community care for psychiatric patients has been apparent now for over fifty years, we still do not have a satisfactory model of community care that all can aim for as the target to be achieved. To an outsider this may seem curious. It seems fairly obvious that hospitals are necessary for patients when they are severely ill, that good care given outside hospital when patients have made some improvement is better than continued hospital treatment, and that the more resources there are available in the community to treat patients early in the course of illness or at times of relapse, the better the service. When one learns that by far the largest proportion of costs spent on the treatment of mental illness is concerned with in-patient treatment (around $85 \%$ in most countries) (Knapp et al., 1994), it is also easy to see why such a policy is attractive to planners and managers of mental health services as well as governments who have to foot the bills.

This was the climate in which assertive community treatment (and its synonyms such as assertive outreach and intensive case management) was born. The approach pioneered by Stein \& Test (1980) involved a psychiatric team taking over responsibility for all parts of life, and so it was no exaggeration that those involved in training and treatment were primarily concerned with training for 'daily living'. Since the original report there have been many other randomised controlled studies carried out between 1980 and 1991 which have confirmed that assertive community treatment is more effective than 'standard care' in the treatment of severe mental illness (Hoult \& Reynolds, 1985; Merson et al., 1992; Muijen et al, 1992; Burns et al, 1993a; Creed, 1995). Although only a

Indirizzo per la corrispondenza: Professor P. Tyrer, Department of Public Mental Health, Division of Neuroscience and Psychological Medicine, Imperial College School of Medicine, Paterson Centre, 20 South Wharf Road, London W2 1PD (UK).

Fax + 44-171-886.1994.

E-mail: p.tyrer@ic.ac.uk small number of studies have shown superiority of assertive community treatment in terms of clinical outcome (Stein \& Test, 1980; Merson et al., 1992), almost all have shown superiority in terms of cost (mainly because admissions to hospitals are reduced) (Weisbrod et al., 1980; Muijen et al., 1992; Burns et al., 1993b; Merson et al., 1996). Patients also are much happier with this type of care than conventional hospital-orientated care and this too is a universal finding.

It might therefore be thought that assertive community treatment was here to stay and would become standard practice in most countries of the world. Certainly, in the United Kingdom this approach has now suddenly been discovered by managers in mental health services the length and breadth of the land and, like Paul's conversion on the road to Damascus, the new dictum is 'assertive community treatment for all'. Against this background of enthusiasm and commitment it may seem churlish to introduce negative findings. Unfortunately for these enthusiasts, such findings are now beginning to appear. Two major studies have been carried out in the United Kingdom in the past five years that throw into doubt some (but certainly not all) of the tenets of assertive community treatment. The first, reported in a comprehensive set of articles in the British Journal of Psychiatry, the PRiSM Psychosis Study, supervised by Graham Thornicroft and his colleagues, has demonstrated that assertive treatment in one borough of London shows no superiority over standard community treatment in another similar borough of London with equivalent levels of socio-economic deprivation (Thornicroft et al., 1998). The study showed no difference in terms of admission rates and duration of admission, clinical outcome, quality of life and overall satisfaction with treatment, although in general patients in the assertive service had more of their needs met than the standard service (Leese et al., 1998; Taylor et al., 1998; Wykes et al., 1998). Costs were, as expected, higher in the intensive care borough because of higher staff 
ratios (McCrone et al., 1998). More botheringly, patients receiving intensive care showed less improvement in social disability than standard care and the rate of violent episodes was greater at both base-line and follow-up in those receiving intensive care (Wykes et al., 1998).

The second study was a randomised controlled trial of intensive and standard case management carried out in four urban areas of the United Kingdom (Manchester, west London, south London (Brixton) and south west London (Wandsworth)). Patients with recurrent psychotic disorders were randomly assigned to intensive case management (case-load of one case worker per 10-15 patients) or standard case management (one case worker per 30-35 patients) and followed up over a two-year period (UK700 Group, 1999a). The results showed similar findings to the PRiSM study in the more rigorous environment of the randomised controlled trial (UK700 Group, 1999b).

Why have the data changed and are no longer in favour of assertive case management? The answer is that 'standard care' has changed. Whereas in the 1980s 'standard care' in most countries consisted of a hospital-dominated service that tended to neglect patients in the community until they were presented with a relapsing illness, most current services are more community-orientated and provide, to a greater or lesser extent, an integrated programme of care which covers both hospital and community elements. The comparison service is now able to hold its own against assertive community treatment much more effectively and, in some cases, such as in the PRiSM study, is apparently superior.

In many ways the results are not unexpected. It is possible to draw a parallel between the success of assertive community treatment in primitive services and its relative lack of success in better ones by looking at the biological phenomenon of plant succession. In alien habitats such as deserts, sea-shores, mud-flats and marshes, only a minority of specially adapted plants are able to gain a foothold and thrive. However, as a consequence of their success the soil conditions become much more conducive to the growth of other plants and these gradually take root and compete with the original specialised species. Before long these are so successful that the specialised plants are squeezed out altogether and no longer thrive in the conditions that they helped to generate.

Assertive community treatment is a similar specialised plant. It thrives in adverse conditions when no community care exists or only the rudiments of community services are present. The more primitive the conditions the greater the benefits of assertive community treatment. However, as it develops the more likely it is for other community services to develop and also thrive. As these become established and extend across the nation, assertive community treatment is squeezed out. Certainly, in our experience, assertive community treatment introduced to a service that already has well established community care tends to be counter-productive. Existing services look on at the new specialised service with irritation rather than respect and do not take kindly to the exclusivity of an intervention that does not seem to embrace the whole of the psychiatric services in the way that comprehensive care should. The answer to the question in this editorial is that assertive community treatment is certainly effective for new community services, but once a comprehensive service has been developed, the assertive approach needs reform and testing again before it can be recommended.

\section{REFERENCES}

Burns T., Beadsmoore A., Bhat A.V., Oliver A. \& Mathers C. (1993a). A controlled trial of home-based acute psychiatric services. I. Clinical and social outcome. British Journal of Psychiatry 163, 49-54.

Burns T., Raftery J., Beadsmoore A., McGuigan S. \& Dickson M. (1993b). A controlled trial of home-based acute psychiatric services. II: Treatment patterns and costs. British Journal of Psychiatry 163, 55-61.

Creed F. (1995). Evaluation of community treatments for acute psychiatric illness. In Community Psychiatry in Action: Analysis and Prospects (ed. P. Tyrer and F. Creed), pp. 11-27. Cambridge University Press: Cambridge.

Hoult J. \& Reynolds I (1985). Schizophrenia: hospital oriented psychiatric care. Acta Psychiatrica Scandinavica 69, 359-372.

Knapp M., Beecham J., Koutsogeorgopoulou V., Hallam A., Fenyo A., Marks I.M., Connolly J., Audini B. \& Muijen M. (1994). Service use and costs of home-based versus hospitalbased care for people with serious mental illness. British Journal of Psychiatry 165, 195-203.

Leese M., Johnson S., Slade M., Parkman S., Kelly F., Phelan M. \& Thornicroft, G. (1998). User perspective on needs and satisfaction with mental health services. PRiSM Psychosis Study 8. British Journal of Psychiatry 173, 409-415.

McCrone P., Thornicroft G., Phelan M., Holloway F., Wykes T. \& Johnson S. (1998). Utilisation and costs of community services on disability and symptoms. PRiSM Psychosis Study 5. British Journal of Psychiatry 173, 391-398.

Merson S., Tyrer P., Onyett S., Lack S., Birkett P., Lynch S. \& Johnson T. (1992). Early intervention in psychiatric emergencies: a controlled clinical trial. Lancet 339, 1311-1314.

Merson S., Tyrer P., Carlen D. \& Johnson T. (1996). The cost of 
treatment of psychiatric emergencies: a comparison of hospital and community services. Psychological Medicine 26, 727-734.

Muijen M., Marks I.M., Connolly J. \& Audini B. (1992). Home based care and standard hospital care for patients with severe mental illness: a randomised controlled trial. British Medical Journal 304, 749-754.

Stein L.I. \& Test M.A (1980). Alternative to mental hospital treatment. 1. Conceptual model, treatment program and clinical evaluation. Archives of General Psychiatry 36, 1073-1079.

Taylor R.E., Leese M., Clarkson P., Holloway \& Thornicroft, G. (1998). Quality of life outcomes for intensive versus standard community mental health services. PRiSM Psychosis Study 9. British Journal of Psychiatry 173, 416-422.

Thornicroft G., Wykes T., Holloway F., Johnson S. \& Szmukler, G. (1998). From efficacy to effectiveness in community mental health services. PRiSM Psychosis Study 10. British Journal of Psychiatry 173, 423-27.

UK700 Group (1999a). Comparison of Intensive and Standard Case Management for Psychotic Patients. Rationale of the trial. British Journal of Psychiatry 174, 74-78.

UK700 Group (1999b). Randomized control trial of intensive versus standard case management for severe psychotic illness: the UK700 Case Management Trial. Lancet (in press).

Weisbrod B.A., Test M.A. \& Stein, L.I. (1980). Alternative to mental hospital treatment. II. Economic benefit-cost analysis. Archives of General Psychiatry 37(4), 400-405.

Wykes T., Leese M., Taylor R. \& Phelan M. (1998). Effects of community services on disability and symptoms. PRiSM Psychosis Study 4. British Journal of Psychiatry 173, 385-390. 